\title{
ETV4 plays a role on the primary events during the adenoma-adenocarcinoma progression in colorectal cancer
}

Aline Simoneti Fonseca 1,2,3,4*, Anelisa Ramão ${ }^{1,2}$, Matheus Carvalho Bürger ${ }^{2}$, Jorge Estefano Santana de Souza ${ }^{2}$, Dalila Lucíola Zanette ${ }^{1,2,3,5}$, Greice Andreotti de Molfetta ${ }^{1,2,3}$, Luiza Ferreira de Araújo ${ }^{1,2,3}$, Rafaela de Barros e Lima Bueno ${ }^{1,2}$, Graziela Moura Aguiar², Jessica Rodrigues Plaça², Cleidson de Pádua Alves², Anemari Ramos Dinarte dos Santos ${ }^{2}$, Daniel Onofre Vidal ${ }^{2}$, Gyl Eanes Barros Silva ${ }^{6}$, Rodrigo Alexandre Panepucci ${ }^{2}$, Fernanda Maris Peria ${ }^{7}$, Omar Feres ${ }^{8}$, José Joaquim Ribeiro da Rocha ${ }^{8}$, Marco Antonio Zago ${ }^{2}$ and Wilson Araújo Silva $\mathrm{Jr}^{1,2,3^{*}}$

\begin{abstract}
Background: Colorectal cancer (CRC) is one of the most common cancers worldwide; it is the fourth leading cause of death in the world and the third in Brazil. Mutations in the APC, DCC, KRAS and TP53 genes have been associated with the progression of sporadic CRC, occurring at defined pathological stages of the tumor progression and consequently modulating several genes in the corresponding signaling pathways. Therefore, the identification of gene signatures that occur at each stage during the CRC progression is critical and can present an impact on the diagnosis and prognosis of the patient. In this study, our main goal was to determine these signatures, by evaluating the gene expression of paired colorectal adenoma and adenocarcinoma samples to identify novel genetic markers in association to the adenoma-adenocarcinoma stage transition.

Methods: Ten paired adenoma and adenocarcinoma colorectal samples were subjected to microarray gene expression analysis. In addition, mutations in APC, KRAS and TP53 genes were investigated by DNA sequencing in paired samples of adenoma, adenocarcinoma, normal tissue, and peripheral blood from ten patients.

Results: Gene expression analysis revealed a signature of 689 differentially expressed genes (DEG) (fold-change> 2, $p<0.05)$, between the adenoma and adenocarcinoma paired samples analyzed. Gene pathway analysis using the 689 DEG identified important cancer pathways such as remodeling of the extracellular matrix and epithelialmesenchymal transition. Among these DEG, the ETV4 stood out as one of the most expressed in the adenocarcinoma samples, further confirmed in the adenocarcinoma set of samples from the TCGA database. Subsequent in vitro siRNA assays against ETV4 resulted in the decrease of cell proliferation, colony formation and cell migration in the HT29 and SW480 colorectal cell lines. DNA sequencing analysis revealed KRAS and TP53 gene (Continued on next page)
\end{abstract}

\footnotetext{
* Correspondence: aline.fonseca@pelepequenoprincipe.org.br;

wilsonjr@usp.br

1Department of Genetics, Ribeirão Preto Medical School, University of São

Paulo, Av Bandeirantes, 3900, CEP: 14049-900, Monte Alegre, Ribeirão Preto,

SP, Brazil

Full list of author information is available at the end of the article
}

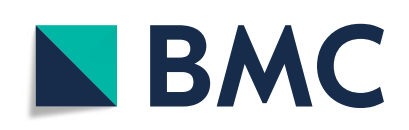

(- The Author(s). 2021 Open Access This article is licensed under a Creative Commons Attribution 4.0 International License, which permits use, sharing, adaptation, distribution and reproduction in any medium or format, as long as you give appropriate credit to the original author(s) and the source, provide a link to the Creative Commons licence, and indicate if changes were made. The images or other third party material in this article are included in the article's Creative Commons licence, unless indicated otherwise in a credit line to the material. If material is not included in the article's Creative Commons licence and your intended use is not permitted by statutory regulation or exceeds the permitted use, you will need to obtain permission directly from the copyright holder. To view a copy of this licence, visit http://creativecommons.org/licenses/by/4.0/. The Creative Commons Public Domain Dedication waiver (http://creativecommons.org/publicdomain/zero/1.0/) applies to the data made available in this article, unless otherwise stated in a credit line to the data. 
(Continued from previous page)

pathogenic mutations, exclusively in the adenocarcinomas samples.

Conclusion: Our study identified a set of genes with high potential to be used as biomarkers in CRC, with a special emphasis on the ETV4 gene, which demonstrated involvement in proliferation and migration.

Keywords: Adenoma, Adenocarcinoma, Colorectal, Genetic markers, ETV4

\section{Background}

Colorectal cancer (CRC) is the third most common cancer worldwide. It represents 10.6 and $9.4 \%$ of the total number of cancers in men and women, respectively [1]. Among the different causes of CRC, approximately 75\% appears sporadically, that is, without any apparent etiological predisposition [2]. Most sporadic CRC (80\%) develops from tubular/villous adenoma [3, 4], and approximately $15 \%$ develops from serrated polyps [5]. These tumors, although rare, can also arise from M-cells of the gut-associated lymphoid tissue (GALT) [6-9].

The frequency of transformation of an advanced adenoma into a carcinoma can range from 2.6 to $5.6 \%$ depending on the age of the patients [10]. Although this frequency is apparently low, CRC was responsible for 935.173 deaths worldwide and represented about 1.931 .590 new cases in 2020 [1]. Despite the high incidence of $\mathrm{CRC}$, and the extensive molecular profiling of these tumors, there are still no available molecular markers that can predict the progression from adenoma to adenocarcinoma.

The goal of this study was to identify a gene signature able to discriminate between adenoma and adenocarcinoma and potentially identify novel CRC biomarkers. To achieve our goal, we performed gene expression profiling in ten paired colorectal adenomas and adenocarcinomas samples. Among the differentially expressed genes (DEG), the ETV4 gene, a variant transcription factor of the ETS family, showed high upregulated expression in the adenocarcinoma samples as compared to adenoma. The overexpression of this gene was further confirmed in the TCGA databases adenocarcinoma samples. Moreover, we observed that the ETV4 knockdown led to decrease in cell proliferation and migration on CRC cell lines, suggesting its potential role in CRC tumorigenesis. Finally, DNA sequencing analysis of the paired samples revealed mutations in the KRAS and TP53 genes in the adenocarcinomas.

\section{Materials and methods \\ Samples}

Paired adenoma, adenocarcinoma and adjacent normal tissue samples from 10 patients were obtained during the surgical procedure at the Clinical Hospital of the Faculty of Medicine, University of São Paulo, Ribeirão Preto (HC-FMRP/USP) under the approval of the $\mathrm{HC}$ -
FMRP/USP Research Ethics Committee (No 12636/ 2010). Initially, during the colonoscopy exam, adenomas were collected from patients who also had a second lesion with a clinical characteristic of adenocarcinoma and surgical indication. Each adenoma specimen was divided into two parts: one part was sent for histopathological analysis and the other part was frozen immediately after collection in liquid nitrogen. Patients who underwent the surgical procedure had the tumor resected including a safety margin. Fragments of the tumor and from the margin were also removed and divided in half; one-half was placed in formalin for histopathological analysis and the other half was immediately frozen in liquid nitrogen, still in the operating room. Only patients who had histopathological confirmation for the simultaneous presence of adenoma, adenocarcinoma and non-tumor tissue, were selected for molecular analysis. During the collections, all the polyps found were only within adenomas.

Additionally, fifteen adenomas and six adenocarcinoma samples were collected to validate the microarray gene expression profiling by RT-qPCR. The fifteen adenoma samples were isolated from seven males and eight females, with an average age and SD of $66.4 \pm 8.683$ years (range 48-79). The six adenocarcinoma samples were isolated from five males and one female, with an average age and SD of $74.3 \pm 8.500$ years (range $62-87$ ). Adenoma samples were collected by colonoscopy and adenocarcinoma samples, by surgery. Using the same methodology used in the matched samples, half of each fragment was sent for histopathological analysis and the other half was frozen in liquid nitrogen for subsequent DNA and RNA isolation.

The inclusion criteria for the selection of samples were based on the clinical and histopathological diagnosis and it included: positive diagnosis for colorectal cancer and presence of adenoma and the agreement to participate in the study, by a signed consent form. Exclusion criteria were: previous treatment (chemo or radiotherapy) and history of Familial Adenomatous Polyposis (FAP), Hereditary Non-Polyposis Syndrome (HNPCC) or inflammatory bowel disease. Clinical data from the patients are shown in Table S1, Additional File 1.

\section{DNA and RNA isolation}

Total RNA and DNA were isolated from frozen tissue using TRIzol ${ }^{\odot}$ Reagent (Invitrogen) according to the 
manufacturer's instructions (DNAse and RNAse were used, respectively). The concentrations were evaluated in a NanoVue Plus ${ }^{\circ}$ spectrophotometer (GE Life Sciences). Specifically for the samples used in the microarrays, the RNA was isolated with RNeasy kit (Qiagen) and its quality assessed by the 2100 Bioanalyzer equipment (Agilent Technologies). Only samples that showed a RIN (RNA Integrity Number) greater than or equal to seven, were considered. The remaining 22 samples, used to validate the microarray results by RT-qPCR, had their RNA integrity assessed on $1.5 \%$ agarose gel stained with ethidium bromide.

\section{Mutation screening using high resolution melting (HRM) assay}

Adenoma and adenocarcinoma samples were subjected to mutational screening using the HRM assay for the entire APC and TP53 gene-coding regions. These regions were amplified with specific sense and antisense primers that flanked each intron/exon, as previously described by Miyoshi et al. (1992) [11] and Bastien et al. (2008) [12] respectively. The HRM analysis was performed in the 7500 Fast Real-Time PCR System (Applied Biosystems), using MeltDoctor HRM Master Mix (Applied Biosystems), according to manufacturer's instructions.

\section{DNA sequencing}

DNA fragments amplified by PCR-HRM, showing abnormal melting curves by the HRM assay were subjected to direct sequencing in an automatic capillary sequencing system ABI 3500 XL (Applied Biosystems), using BigDye Terminator kit, following the manufacturer's instructions. The same methodology was used to sequence exon 2 of the KRAS gene, using specific sense and antisense primers that flanked each intron/exon, as previously described at Fassina et al. (2010) [13]. The sequencing results were analyzed in Chromas Lite v2.1 [14].

The normal paired tissue of the mutated samples was also sequenced, to investigate whether the mutations were of somatic or germline origin. The sequences obtained were compared to the reference from the GenBank NM_000038.5, GenBank NM_000546.5 and GenBank NM_004985.4, respectively to APC, TP53 and KRAS genes.

Pathogenicity prediction was performed in Sift [15] and Mutation Taster [16] online tools and only mutations that were predicted as damaging in both tools were classified as pathogenic.

\section{Microarray hybridizations}

To investigate differential gene expression between colorectal adenoma and adenocarcinoma, the platform Whole Human
Genome Microarray Kit 4x44K v2 (G4112F, Agilent Technologies) was employed. Prior to the hybridizations, $200 \mathrm{ng}$ of total RNA from each sample were used for cDNA synthesis. The arrays slides were washed following the manufacturer's guidelines and then scanned using the GenePix 4000B scanner (Axon Instruments) with the GenePix Pro 6.0 software and the hybridization signal intensity of each array was extracted using the Agilent Feature Extraction software 9.5.3.1. (Agilent Technologies).

\section{Microarray data analysis}

To evaluate the data quality, we used the array QualityMetrics R/Bioconductor package [17-19]. Normalization was performed by a three-step approach with the R/Bioconductor limma package methods $[17,18,20]$. Initially it was applied as a cyclic loss method between technical replicates, quantile between samples of adenoma and adenocarcinoma group and quantile between arrays [21]. Then, the detection of differentially expressed genes (DEG) was also performed by the limma package, applying the Benjamini-Hochberg method for $p$-value correction $[20,22]$. To evaluate the expression pattern of DEG, Euclidian distance and complete linkage was performed for genes and samples clustering, and then visualized in a heatmap.

\section{Gene expression validation}

The reverse transcription reaction was performed using High Capacity cDNA Reverse Transcription Kit (Applied Biosystems) according to the manufacturer's instructions. After synthesis, the cDNA was diluted 1:5 and then used in quantitative PCR.

TaqMan probes (Applied Biosystems and IDT) were used for RT-qPCR validation of the genes previously selected by microarray. To avoid amplification of genomic DNA (gDNA), no-RT negative control and Taqman probes in exon-exon junction were used. The HPRT1 (4326321E, Applied Biosystems) housekeeping gene was chosen as endogenous control. Primers and probes for gene expression were IL-6 (Hs00174131, Applied Biosystems), IL-8 (Hs00174103, Applied Biosystems), OSM (Hs00171165_ M1, Applied Biosystems), SFRP4 (Hs.PT.51.1726538.g, IDT), ETV4 (Hs.PT.56a.23047301.g, IDT), SIM2 (Hs.PT.51.20479148.g, IDT), ESM1 (Hs.PT.51.19279572.g, IDT) e RETNLB (Hs. PT.51.1296566, IDT).

All reactions were performed in an ABI Prism ${ }^{\circ} 7500$ Fast Sequence Detection System (Applied Biosystems). The relative expression for each gene was calculated by the $2^{-\Delta \Delta C T}$ method [23].

\section{TCGA data analysis}

The Hiseq platform gene expression level 3 RNASeqV2 data from normal and tumor samples from Colon 
Adenocarcinoma (COAD - normal - 41 and tumor 285) and Rectal Adenocarcinoma (READ - normal - 10 and tumor - 94) were downloaded from the database The Cancer Genome Atlas (TCGA), on March 22, 2017, through the TCGAbiolinks R/Bioconductor package [24]. Differential expression analysis was performed using EdgeR R/Bioconductor package [25]. We considered DEG absolute values of $\log 2$ fold-change $>1$ and $p$-value adjusted by FDR $\leq 0.05$.

\section{Gene pathways}

Gene pathway analysis was performed using the 689 DEG in the MetaCore from Clarivate Analytics. For the analysis in MetaCore we used the fold change of each gene to obtain the enriched gene pathways.

\section{Culture and siRNA assay}

For functional assays, HT29 and SW480 colorectal carcinoma cell lines were used (cell lines kindly provided by Prof. Eloiza Helena Tajara da Silva, from UNESP - University of São Paulo State). The cell lines were cultivated in RPMI (Roswell Park Memorial Institute) 1640 medium (Gibco) supplemented with $10 \%$ fetal bovine serum (FBS) and $0.5 \%$ penicillin-streptomycin under controlled temperature and humidity conditions $\left(37^{\circ} \mathrm{C}\right.$, $5 \% \mathrm{CO} 2,95 \%$ humidity). For siRNA inhibition studies, cells were transfected with ETV4 siRNA (siETV4) or negative control (siCTRL) (Sigma-Aldrich, St. Louis, $\mathrm{MO}$ ) in a final concentration of $30 \mathrm{nM}$, using Lipofectamine RNAiMAX reagent (Invitrogen, Carlsbad, CA, USA), according to manufacturer's instructions. After $48 \mathrm{~h}$ of transfection, cells were collected for functional assays, which were all performed in triplicates.

\section{Cell proliferation assay}

Cell proliferation assay was performed using CFSE (5,6carboxyfluorescein diacetate succinimidyl ester) according to the manufacturer's instructions. Cells were transfected (siCTRL and siETV4) and labeled with CFSE simultaneously. A third group of cells with no treatment was used for the cytometer calibration. After $24 \mathrm{~h}$ of labeling, cells were evaluated in a FACSCalibur flow cytometer (Becton Dickinson, Franklin Lakes, NJ, USA), and consecutively analyzed every $24 \mathrm{~h}$ for a total of $96 \mathrm{~h}$.

\section{Anchorage-dependent colony formation assay}

Colorectal cancer cell lines were transfected and cultured in a density of 500 cells/well. After 12 days of culture, the cells were washed with PBS, fixed with $4 \%$ paraformaldehyde, and stained with $0.5 \%$ crystal violet. The plates were then photographed on ImageQuant LAS 4000 (GE Healthcare) and colonies were counted.

\section{Transwell migration assay}

Cell migration assays were performed on 24-well plates with $8 \mu \mathrm{m}$ transwell inserts (Greiner Bio One). After 48 $\mathrm{h}$ of transfection, $1 \times 10^{5}$ cells were seeded on top of the insert in $200 \mu \mathrm{l}$ of serum-free medium. In the bottom of the well, cells were seeded in $600 \mu \mathrm{l}$ of $10 \%$ FBS medium. After $24 \mathrm{~h}$ of migration, cells were fixed, stained with $0.5 \%$ crystal violet and the non-migrating cells from the top of the insert were cleaned with cotton swabs. The inserts were then photographed on ImageQuant LAS 4000 (GE Healthcare) and cells were manually counted.

\section{Statistical analysis}

Statistical analysis was carried out in the GraphPad Prism 6.0 for Windows (GraphPad Software, San Diego, California, USA) [26]. Mann-Whitney's test was applied for comparisons between two-independent groups. Statistical analysis of the proliferation assay was determined by two-way ANOVA followed by Bonferroni multiple comparisons test. $P$ values $\leq 0.05$ were considered significant.

\section{Results}

DNA sequencing and gene expression analysis of paired samples of colorectal adenoma and adenocarcinoma DNA sequencing analysis of the ten adenomaadenocarcinoma sample set, revealed seven mutations in the $A P C$ gene, six synonymous and one nonsynonymous mutation, all of them germline polymorphisms. Both TP53 and KRAS genes showed three and two somatic damaging mutations (P152L/R273C/R273H and G12A/G2D), in the ten paired samples, respectively. In addition, two polymorphisms were observed in the TP53 gene (Table S2, Additional File 2). Simultaneous mutations co-occurring in the three genes were observed only in three of the ten adenoma/adenocarcinoma samples.

Gene expression analysis from the ten matched colorectal adenoma-adenocarcinoma identified 689 differentially expressed genes (DEG) between these tissue types: 329 genes were upregulated in adenocarcinomas and 360 upregulated in adenomas (Fig. 1a). Unsupervised hierarchical clustering analysis of the 689 DEG was able to delimitate gene clusters specific for each tissue (Fig. 1b).

Although we observed some non-synonymous mutations in the TP53 and KRAS genes, those genes were not differentially expressed in our microarray analyses.

The 689 DEGs were used to evaluate the enrichment of gene pathways potentially related to the adenomaadenocarcinoma transition. Of the ten pathways with the highest number of genes, the pathways of cell adhesion and remodeling, epithelial-mesenchymal transition and the IGF family pathway (related to CRC) stood out. 

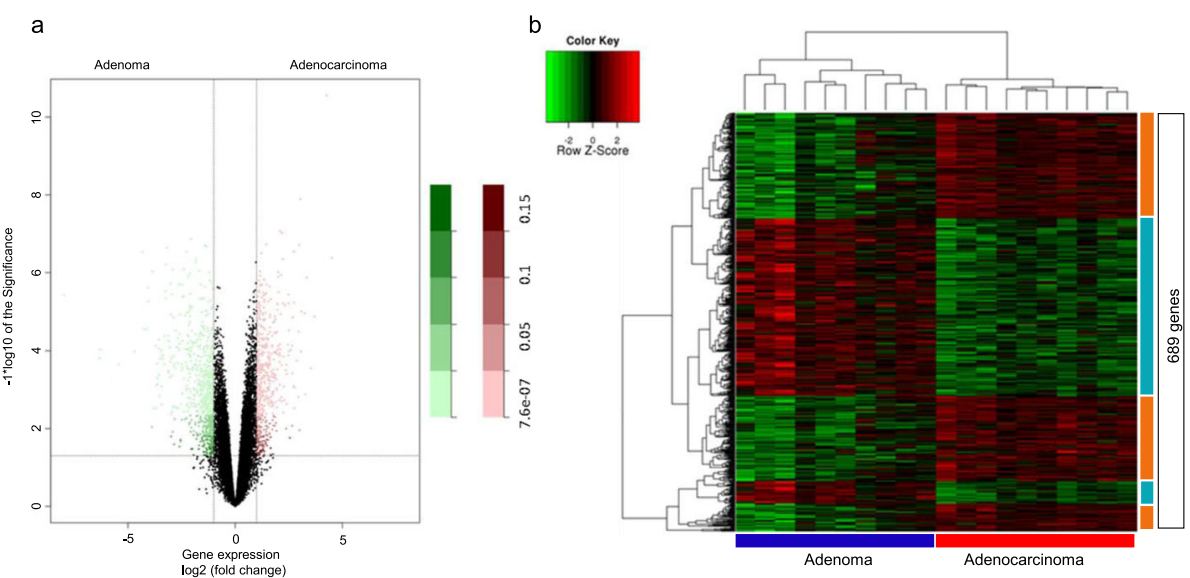

Fig. 1 Microarray gene expression analysis in the 10 paired colorectal adenoma and adenocarcinoma samples of this study. A: Volcano Plot representing the set of genes analyzed by gene expression in the ten paired samples of colorectal adenoma and adenocarcinoma. Pink dots represent upregulated genes in adenocarcinoma when compared to adenoma; Green dots represent upregulated genes in adenoma when compared to adenocarcinoma. B: Unsupervised hierarchical clustering analysis in adenoma and adenocarcinoma samples based on the 689 differentially expressed genes ( $\log 2 \mathrm{FC} \geq 2$ and $\mathrm{FDR} \leq 0,05)$

In order to select genes with a potential role in the adenoma-adenocarcinoma transition process, we applied two filters: first the top 50 most DEG between colorectal adenoma and adenocarcinoma samples (Table 1) were selected. A second filter selected the top 50 genes DEG across all the ten adenocarcinoma-adenoma paired samples (Table 2).

To confirm the gene expression data obtained from microarray analysis, eight genes were selected for validation by RT-qPCR (SIM2, ESM1, SFRP4, IL8, IL6, OSM, ETV4 and RETNLB) on 25 adenomas and 16 adenocarcinomas (the initial 10 adenoma/adenocarcinoma paired samples and additional 15 adenomas and 6 adenocarcinoma samples). The RT-qPCR results were in agreement with the microarray data. In addition, genes presented a very similar expression pattern between the adenoma-adenocarcinoma pairs in both techniques (Fig. 2a-d), reinforcing the robustness of the data.

To further validate our findings in a different cohort using non-neoplastic tissue, we performed an in silico gene expression analysis between normal colorectal tissue and both colon and rectal adenocarcinoma, using data available at TCGA.

Gene expression analyses were performed separately. First, normal colon tissue and colon adenocarcinoma were compared (Fig. 3a). A second analysis compared the normal rectal tissue with the rectal adenocarcinoma (Fig. 3b). In both analyses, ETV4 was overexpressed in adenocarcinoma samples (Fig. 2a-b). As this gene was also found to be upregulated in our cohort (Table 1), we proceeded with a functional investigation of its role in colorectal tumorigenesis.
ETV4 acts in the proliferation, colony formation and cellular migration

To investigate the possible role of ETV4 in colorectal carcinoma tumorigenesis, HT29 and SW480 colorectal cancer cell lines were used in functional assays. Transient transfection using siRNA oligos efficiently knocked down $80 \%$ of the ETV4 gene expression levels in HT29 cell line and $88 \%$ in SW480 cell line, as confirmed by RT-qPCR (Supplementary Figure 1, Additional File 3). Cell proliferation rates were analyzed by CFSE labelling and evaluated by flow cytometry every $24 \mathrm{~h}$ during $96 \mathrm{~h}$. The results showed a significant reduction of HT29 cell proliferation rates at $48 \mathrm{~h}$ and $72 \mathrm{~h}$ after transfection with ETV4-siRNA (Fig. 4a). Accordingly, in SW480 cells depleted for ETV4 expression, cell proliferation was significantly reduced after $48 \mathrm{~h}$ (Fig. $4 \mathrm{~b}$ ). Downregulation of ETV4 expression in colorectal cell lines did not affect cell apoptosis or viability, (Supplementary Figure 2A-B, Additional File 4), indicating that the results observed are exclusively due to the modulation of cell proliferation.

Colony formation assays were also performed by counting the number of colonies formed by sparsely cultured cells after 12 days. ETV4 gene knockdown in HT29 and SW480 cells impaired their ability to grow as colonies in 20 and 50\%, respectively (Fig. 5a-b). We also evaluated the effect of ETV4 gene knockdown on the migratory capacity of colorectal tumor cell lines. The migration assay was performed on transwell membranes $24 \mathrm{~h}$ after the ETV4 knockdown in the HT29 and SW480 cell lines. As it can be seen in Fig. 5c-d, depletion of ETV4 expression decreased cell migration in both cell lines. Taken together, these results suggest an important role of ETV4 in diverse tumorigenic processes, 
Table 1 Top 50 DEG genes, 25 upregulated and 25 downregulated, between the paired colorectal adenocarcinoma and adenoma samples (presented by FC)

\begin{tabular}{|c|c|c|c|c|}
\hline Gene & RefSeq & Description & $\mathrm{FC}^{\mathrm{a}}$ & FDR $^{\mathbf{b}}$ \\
\hline \multicolumn{5}{|c|}{ Upregulated } \\
\hline SFRP4 & NM_003014.3 & secreted frizzled-related protein 4 & 4.51 & 0.00072 \\
\hline SIM2 & NM_005069.3 & single-minded family bHLH transcription factor 2 & 4.26 & 7.63E-07 \\
\hline EREG & NM_001432.2 & epiregulin & 3.54 & 0.01111 \\
\hline FAP & NM_001291807.1 & fibroblast activation protein, alpha & 3.34 & 0.00112 \\
\hline COL11A1 & NM_001190709.1 & collagen, type XI, alpha 1 & 3.09 & 0.00228 \\
\hline FUT1 & NM_000148.3 & fucosyltransferase 1 & 3.04 & 0.00017 \\
\hline ESM1 & NM_001135604.1 & endothelial cell-specific molecule 1 & 2.98 & 0.00060 \\
\hline FABP6 & NM_001040442.1 & fatty acid binding protein 6 , ileal & 2.95 & 0.00420 \\
\hline IL8 & NM_000584.3 & interleukin 8 & 2.94 & 0.02829 \\
\hline OSM & NM_020530.4 & oncostatin & 2.87 & 0.00913 \\
\hline IL6 & NM_000600.3 & interleukin 6 & 2.76 & 0.03991 \\
\hline COLIA1 & NM_000088.3 & collagen, type I, alpha 1 & 2.75 & 0.00181 \\
\hline STC2 & NM_003714.2 & stanniocalcin 2 & 2.74 & 0.00060 \\
\hline TDO2 & NM_005651.3 & tryptophan 2,3-dioxygenase & 2.69 & 0.00264 \\
\hline OTX1 & NM_001199770.1 & orthodenticle homeobox 1 & 2.68 & 0.01271 \\
\hline WNT2 & NM_003391.2 & wingless-type MMTV integration site family member 2 & 2.65 & 0.00601 \\
\hline CTHRC1 & NM_001256099.1 & collagen triple helix repeat containing 1 & 2.51 & 0.00401 \\
\hline COL8A1 & NM_001850.4 & collagen, type VIII, alpha 1 & 2.50 & 0.00706 \\
\hline NOX4 & NM_001143836.2 & NADPH oxidase 4 & 2.49 & 0.00154 \\
\hline TNFAIP6 & NM_007115.3 & tumor necrosis factor, alpha-induced protein 6 & 2.48 & 0.00776 \\
\hline INHBA & NM_002192.2 & inhibin, beta A & 2.47 & 0.00594 \\
\hline CYR61 & NM_001554.4 & cysteine-rich, angiogenic inducer, 61 & 2.41 & 0.01300 \\
\hline GREM1 & NM_001191322.1 & gremlin 1, DAN family BMP antagonist & 2.40 & 0.03523 \\
\hline CXCL10 & NM_001565.3 & chemokine (C-X-C motif) ligand 10 & 2.40 & 0.01026 \\
\hline ETV4 & NM_001079675.2 & ets variant 4 & 2.19 & 0.00060 \\
\hline \multicolumn{5}{|c|}{ Downregulated } \\
\hline CLCA1 & NM_001285.3 & chloride channel accessory 1 & -7.97 & 0.00155 \\
\hline DEFA5 & NM_021010.1 & defensin, alpha 5, Paneth cell-specific & -6.31 & 0.00844 \\
\hline ITLN1 & NM_017625.2 & intelectin 1 & -6.29 & 0.00668 \\
\hline ZG16 & NM_152338.3 & zymogen granule protein 16 & -5.90 & 0.01116 \\
\hline DEFA6 & NM_001926.3 & defensin, alpha 6, Paneth cell-specific & -5.89 & 0.01083 \\
\hline FCGBP & NM_003890.2 & Fc fragment of lgG binding protein & -4.68 & 0.00706 \\
\hline RETNLB & NM_032579.2 & resistin like beta & -4.33 & 0.00060 \\
\hline ITLN2 & NM_080878.2 & intelectin 2 & -4.26 & 0.00391 \\
\hline FAM55D & NM_001077639.1 & neurexophilin and PC-esterase domain family, member 4 & -4.12 & 0.00392 \\
\hline HEPACAM2 & NM_001039372.2 & HEPACAM family member 2 & -4.05 & 0.00131 \\
\hline B3GNT6 & NM_138706.4 & UDP-GIcNAc:betaGal beta-1,3-N-acetylglucosaminyltransferase 6 & -4.03 & 0.00177 \\
\hline BEST2 & NM_017682.2 & bestrophin 2 & -3.86 & 0.00099 \\
\hline REG4 & NM_001159352.1 & regenerating islet-derived family member 4 & -3.81 & 0.04009 \\
\hline UGT2B17 & NM_001077.3 & UDP glucuronosyltransferase 2 family, polypeptide B17 & -3.71 & 0.00601 \\
\hline SPINK4 & NM_014471.1 & serine peptidase inhibitor, Kazal type 4 & -3.68 & 0.03954 \\
\hline DPP10-AS1 & NR_036580.1 & DPP10 antisense RNA 1 & -3.67 & 0.01926 \\
\hline
\end{tabular}


Table 1 Top 50 DEG genes, 25 upregulated and 25 downregulated, between the paired colorectal adenocarcinoma and adenoma samples (presented by FC) (Continued)

\begin{tabular}{|c|c|c|c|c|}
\hline Gene & RefSeq & Description & $\mathrm{FC}^{\mathrm{a}}$ & FDR $^{\mathbf{b}}$ \\
\hline SLC4A4 & NM_001098484.2 & solute carrier family 4 & -3.63 & 0.01004 \\
\hline UGT2B15 & NM_001076.3 & UDP glucuronosyltransferase 2 family polypeptide B15 & -3.56 & 0.00500 \\
\hline KLK12 & NM_019598.2 & kallikrein-related peptidase 12 & -3.56 & 0.00633 \\
\hline L1TD1 & NM_001164835.1 & LINE-1 type transposase domain containing 1 & -3.52 & 0.02738 \\
\hline ADH1A & NM_000667.3 & alcohol dehydrogenase $1 \mathrm{~A}$ (class I) alpha polypeptide & -3.48 & 0.00852 \\
\hline PLA2G2A & NM_000300.3 & phospholipase A2, group IIA (platelets synovial fluid) & -3.43 & 0.01981 \\
\hline VSIG2 & NM_014312.3 & V-set and immunoglobulin domain containing 2 & -3.43 & 0.00681 \\
\hline ADH1C & NM_000669.4 & alcohol dehydrogenase 1 C (class I), gamma polypeptide & -3.39 & 0.00776 \\
\hline$M B$ & NM_005368.2 & myoglobin & -3.25 & 0.00144 \\
\hline
\end{tabular}

${ }^{\mathrm{a}} \mathrm{FC}$ (log2 fold change); ${ }^{\mathrm{b}} \mathrm{FDR}$ (false discovery rate). The genes in bold were selected for validation by RT-qPCR

such as cell proliferation, migration, and colony formation.

\section{Discussion}

Adenoma and adenocarcinoma colorectal gene signatures In this study, the analysis of gene expression profiles of adenomas and adenocarcinomas by microarrays and signaling pathways analysis revealed many pathways and cellular processes associated with extracellular matrix remodeling, angiogenesis and epithelial-mesenchymal transition, as well as the IGF (Insulin-like growth factor) signaling pathway, which is known to be directly linked to colorectal cancer (Metacore from Clarivate Analytics) (Table S3, Additional File 5).

The strategy of comparing adenoma-adenocarcinoma samples from the same patient reduces sample and tumor heterogeneity, increasing the power of the study to generate a potential gene signature for the adenomaadenocarcinoma transition.

Several studies on differentially expressed genes in CRC are found in the literature. However, the different microarray platforms and statistical methods used in these studies hamper the discovery of reliable biomarkers to be used in clinical practice. To overcome this limitation, some research groups [27-30] applied metaanalysis approaches, comparing different microarray analysis in samples from normal tissue, adenoma and adenocarcinoma or only between normal tissue and adenocarcinoma. Some of the genes described in these meta-analysis studies were also found in our data and are briefly discussed below. FcGBP, was found to be downregulated in our study and in normal-adenomacarcinoma sequence according to Lee and colleagues [31]. FcGBP was also indicated as a prognosis marker in gallbladder cancer [32]. CLCA1 has been described as a marker of the transition from proliferation to differentiation in CRC [33]. CLCA1 decreased expression was also described in serum and CRC tissues, showing an inverse correlation with CRC metastasis and tumor stage [34]. CLCA1 and $A D H 1 C$ were shown to be downregulated in familial adenomatous polyposis [35]. SLC4A4 associated with proliferation and migration in colon and breast cancer [36]. COL1A1 was overexpressed in tumor tissues from colorectal adenocarcinomas and its silencing significantly inhibited proliferation, migration and invasion, while cell apoptosis was promoted [37]. ZG16 has been associated with stemness and progression in CRC [38] and its expression has been shown to be sequentially reduced from normal tissue to adenoma and to carcinoma [39]. ETV4 and FABP6 were co-expressed in tumor samples and significantly associated with metastasis in CRC [40]. DEFA6 was shown to be associated with overall survival rate and is an independent prognostic marker for CRC [41]. L1TD1 has been described as a good prognosis marker candidate in CRC, but its elevated expression has also been associated with poor prognosis in other cancer types. These distinctive roles are dependent on its interaction partners. Several co-expression partners of L1TD1 already described in CRC have also been observed in our study, such as SPINK4, RETNLB, CLCA1, FcGBP, HEPACAM2, ITLN1 and, DEFA5 [42]. The common genes observed in our study with previous meta-analysis and other studies reinforces the importance of our findings.

\section{ETV4 functional validation}

The ETV4 gene (E1AF/PEA3 - ets variant 4) is a transcription factor member of the ETS oncogene family that comprises a conserved amino acid sequence, the ETS domain, the DNA binding site to the ETS oncogenes [43]. Its elevated expression has been described in several types of cancer, such as breast, ovary, prostate, gastric and colorectal [44-48].

Our assays demonstrated that ETV4 silencing in the HT29 and SW480 CRC cell lines reduced proliferation, colony formation and cell migration. Previous 
Table 2 Top 50 DEG, 29 upregulated and 21 downregulated, observed exclusively in all the ten samples of adenocarcinoma (presented by FC)

\begin{tabular}{|c|c|c|c|c|}
\hline Gene & RefSeq & Description & $\mathrm{FC}^{\mathrm{a}}$ & FDR $^{\mathbf{b}}$ \\
\hline \multicolumn{5}{|c|}{ Upregulated } \\
\hline SIM2 & NM_005069.3 & single-minded family bHLH transcription factor 2 & 4.26 & 7.63E-07 \\
\hline FAP & NM_001291807.1 & fibroblast activation protein, alpha & 3.34 & 0.00112 \\
\hline FUT1 & NM_000148.3 & fucosyltransferase 1 & 3.04 & 0.00017 \\
\hline ESM1 & NM_001135604.1 & endothelial cell-specific molecule 1 & 2.98 & 0.00060 \\
\hline FABP6 & NM_001040442.1 & fatty acid binding protein 6 , ileal & 2.95 & 0.00420 \\
\hline COLIA1 & NM_000088.3 & collagen, type I, alpha 1 & 2.75 & 0.00181 \\
\hline WNT2 & NM_003391.2 & wingless-type MMTV integration site family member 2 & 2.65 & 0.00601 \\
\hline ELN & NM_000501.3 & elastin & 2.22 & 0.00072 \\
\hline ETV4 & NM_001079675.2 & ets variant 4 & 2.18 & 0.00060 \\
\hline ACAN & NM_001135.3 & aggrecan & 2.12 & 0.00107 \\
\hline LARP6 & NM_001286679.1 & La ribonucleoprotein domain family, member 6 & 2.00 & 0.00111 \\
\hline FADS1 & NM_013402.4 & fatty acid desaturase & 2.00 & 0.00099 \\
\hline SCRN1 & NM_001145513.1 & secernin 1 & 1.97 & 0.00188 \\
\hline LYGE & NM_001127213.1 & lymphocyte antigen 6 complex, locus E & 1.95 & 0.00691 \\
\hline TCFL5 & NM_006602.2 & transcription factor-like 5 (basic helix-loop-helix) & 1.91 & 0.00426 \\
\hline$P R O C R$ & NM_006404.4 & protein $C$ receptor, endothelial & 1.90 & 0.00745 \\
\hline FAM150A & NM_001195732.1 & family with sequence similarity 150 member $\mathrm{A}$ & 1.87 & 0.00283 \\
\hline COL5A2 & NM_000393.3 & collagen, type $V$, alpha 2 & 1.73 & 0.00601 \\
\hline FAM72D & NM_207418.2 & family with sequence similarity 72 member D & 1.62 & 0.00262 \\
\hline SPARC & NM_003118.3 & secreted protein, acidic, cysteine-rich (osteonectin) & 1.62 & 0.00420 \\
\hline PARVB & NM_001003828.2 & parvin, beta & 1.56 & 0.01610 \\
\hline VEGFA & NM_001025366.2 & vascular endothelial growth factor A & 1.46 & 0.00123 \\
\hline UBE2C & NM_001281741.1 & ubiquitin-conjugating enzyme & 1.45 & 0.00060 \\
\hline AUNIP & NM_001287490.1 & aurora kinase $A$ and ninein interacting protein & 1.35 & 0.00177 \\
\hline GK & NM_000167.5 & glycerol kinase & 1.26 & 0.00437 \\
\hline LRP8 & NM_001018054.2 & low density lipoprotein receptor-related protein 8, apolipoprotein e receptor & 1.15 & 0.01137 \\
\hline DIAPH3 & NM_001042517.1 & diaphanous-related formin 3 & 1.11 & 0.00178 \\
\hline FAM162B & NM_001085480.2 & family with sequence similarity 162 member B & 1.05 & 0.04851 \\
\hline CENPJ & NM_018451.4 & centromere protein $J$ & 1.04 & 0.00243 \\
\hline \multicolumn{5}{|c|}{ Downregulated } \\
\hline CLCA1 & NM_001285.3 & chloride channel accessory 1 & -7.97 & 0.00155 \\
\hline HEPACAM2 & NM_001039372.2 & HEPACAM family member 2 & -4.05 & 0.00131 \\
\hline B3GNT6 & NM_138706.4 & UDP-GlcNAc:betaGal beta-1,3-N-acetylglucosaminyltransferase 6 & -4.03 & 0.00177 \\
\hline BEST2 & NM_017682.2 & bestrophin 2 & -3.86 & 0.00099 \\
\hline L1TD1 & NM_001164835.1 & LINE-1 type transposase domain containing 1 & -3.52 & 0.02738 \\
\hline ADH1A & NM_000667.3 & alcohol dehydrogenase 1A (class I) alpha polypeptide & -3.48 & 0.00852 \\
\hline ADH1C & NM_000669.4 & alcohol dehydrogenase 1 C (class I), gamma polypeptide & -3.39 & 0.00776 \\
\hline GALNT8 & NM_017417.1 & polypeptide $\mathrm{N}$-acetylgalactosaminyltransferase 8 & -3.24 & 0.00084 \\
\hline SPTLC3 & NM_018327.2 & serine palmitoyltransferase, long chain base subunit 3 & -2.99 & 0.00244 \\
\hline SPINK2 & NM_001271718.1 & serine peptidase inhibitor, Kazal type 2 (acrosin-trypsin inhibitor) & -2.49 & 0.01166 \\
\hline ATOH8 & NM_153778.3 & atonal homolog 8 & -2.32 & 0.00643 \\
\hline KCNMA1 & NM_001014797.2 & potassium large conductance calcium-activated channel, subfamily M, alpha member 1 & -2.27 & 0.00060 \\
\hline
\end{tabular}


Table 2 Top 50 DEG, 29 upregulated and 21 downregulated, observed exclusively in all the ten samples of adenocarcinoma (presented by FC) (Continued)

\begin{tabular}{|c|c|c|c|c|}
\hline Gene & RefSeq & Description & $\mathrm{FC}^{\mathrm{a}}$ & FDR $^{b}$ \\
\hline NEURL & NM_004210.4 & neuralized E3 ubiquitin protein ligase 1 & -2.19 & 0.00109 \\
\hline PIGR & NM_002644.3 & polymeric immunoglobulin receptor & -2.14 & 0.01272 \\
\hline MFSD4 & NM_181644.4 & major facilitator superfamily domain containing 4 & -2.11 & 0.00201 \\
\hline ARHGAP44 & NM_014859.4 & Rho GTPase activating protein 44 & -2.06 & 0.00060 \\
\hline SERTAD4 & NM_019605.3 & SERTA domain containing 4 & -1.82 & 0.00072 \\
\hline PLA2G10 & NM_003561.1 & phospholipase A2, group X & -1.73 & 0.04438 \\
\hline NEDD4L & NM_001144964.1 & eural precursor cell expressed, developmentally down-regulated 4-like, E3 ubiquitin protein ligase & -1.61 & 0.00123 \\
\hline ACADVL & NM_000018.3 & acyl-CoA dehydrogenase, very long chain & -1.20 & 0.00099 \\
\hline PID1 & NM_001100818.1 & phosphotyrosine interaction domain containing 1 & -1.19 & 0.01212 \\
\hline
\end{tabular}

${ }^{\mathrm{a}} \mathrm{FC}$ (log2 fold change); ${ }^{\mathrm{b}} \mathrm{FDR}$ (false discovery rate). The genes in bold are the same ones selected in Table 1 for validation by RT-qPCR

a

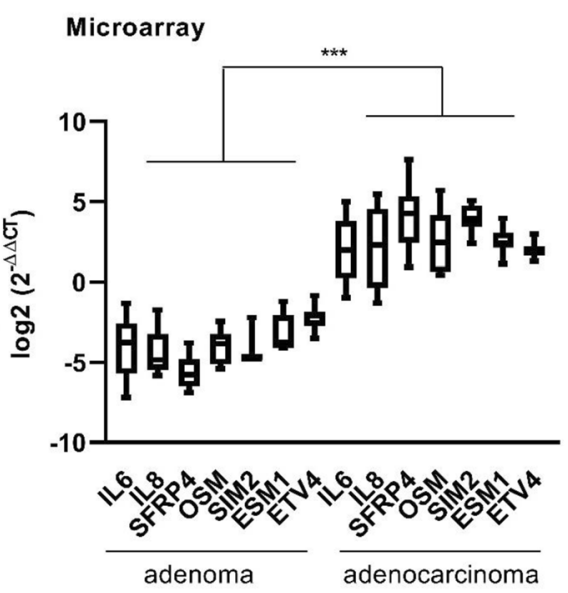

C

Microarray

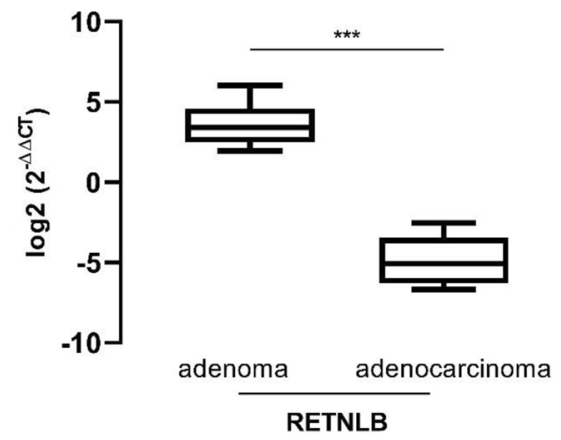

b

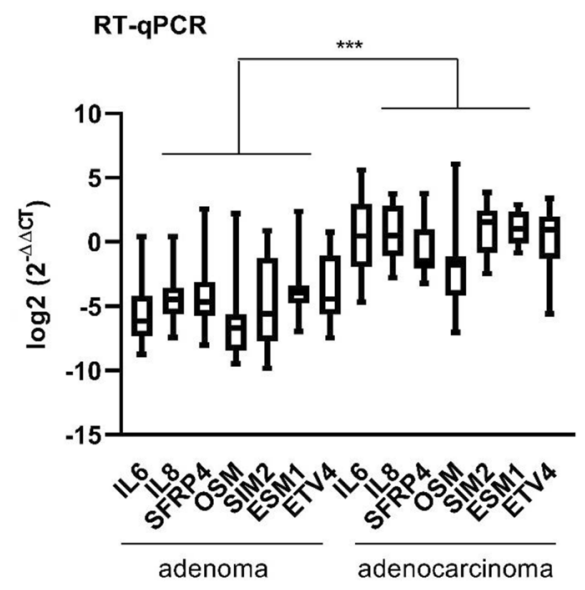

d

\section{RT-qPCR}

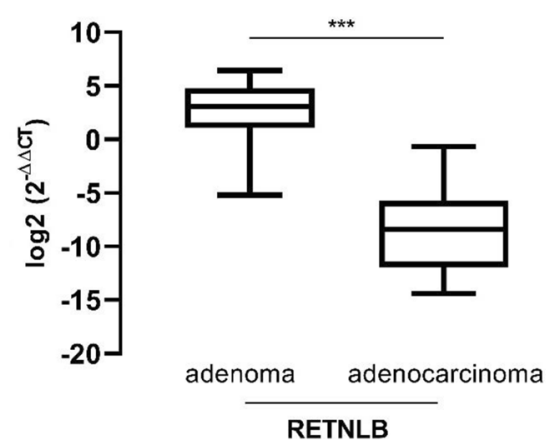

Fig. 2 Validation of microarray data by RT-qPCR. a Microarray data of the 10 paired adenoma/adenocarcinoma paired samples, showing the upregulation of seven genes in adenocarcinomas compared to adenomas. $\mathbf{b}$ RT-qPCR results showing the validation of the microarray results of the same set of genes in a larger set of samples (25 adenoma and 16 adenocarcinoma samples, of which 10 adenoma/adenocarcinoma paired samples and 15 adenoma and 6 adenocarcinoma additional new samples). $\mathbf{c}$ and $\mathbf{d}$ Relative expression of the RETNLB gene found downregulated in adenocarcinomas when compared to adenomas by microarray (10 paired adenoma-adenocarcinoma samples) and RT-qPCR (10 adenoma/adenocarcinoma paired samples plus 15 adenoma and 6 adenocarcinoma samples) analysis, respectively. Fold changes (log2 FC) between the expression means in adenomas and adenocarcinomas were $A=6.75, B=4.93, C=8.50$ and $D=11.12$. Mann-Whitney's test was used for statistical analysis (A and B: ${ }^{* *} p<0.0006$; C and D: ${ }^{* *} p<0.0001$ ) 

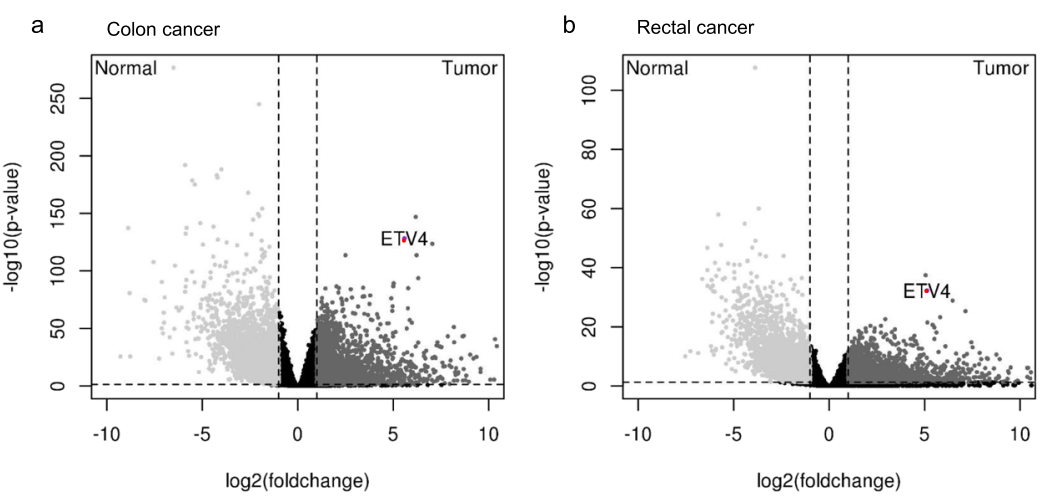

Fig. 3 Gene expression analysis of the colon and rectum normal or cancer samples from the TCGA database. a Volcano plot representing the differentially expressed genes between 41 normal tissue and 285 colon adenocarcinomas samples (FDR=4.91e-129 and log2 fold change = 5.59). b Volcano plot representing the differentially expressed genes between 10 normal tissue samples and 94 colon adenocarcinomas samples (FDR= 5.544394e-33 and log2 fold change $=5.13$ ). Red dot: ETV4 gene overexpressed in cancer samples

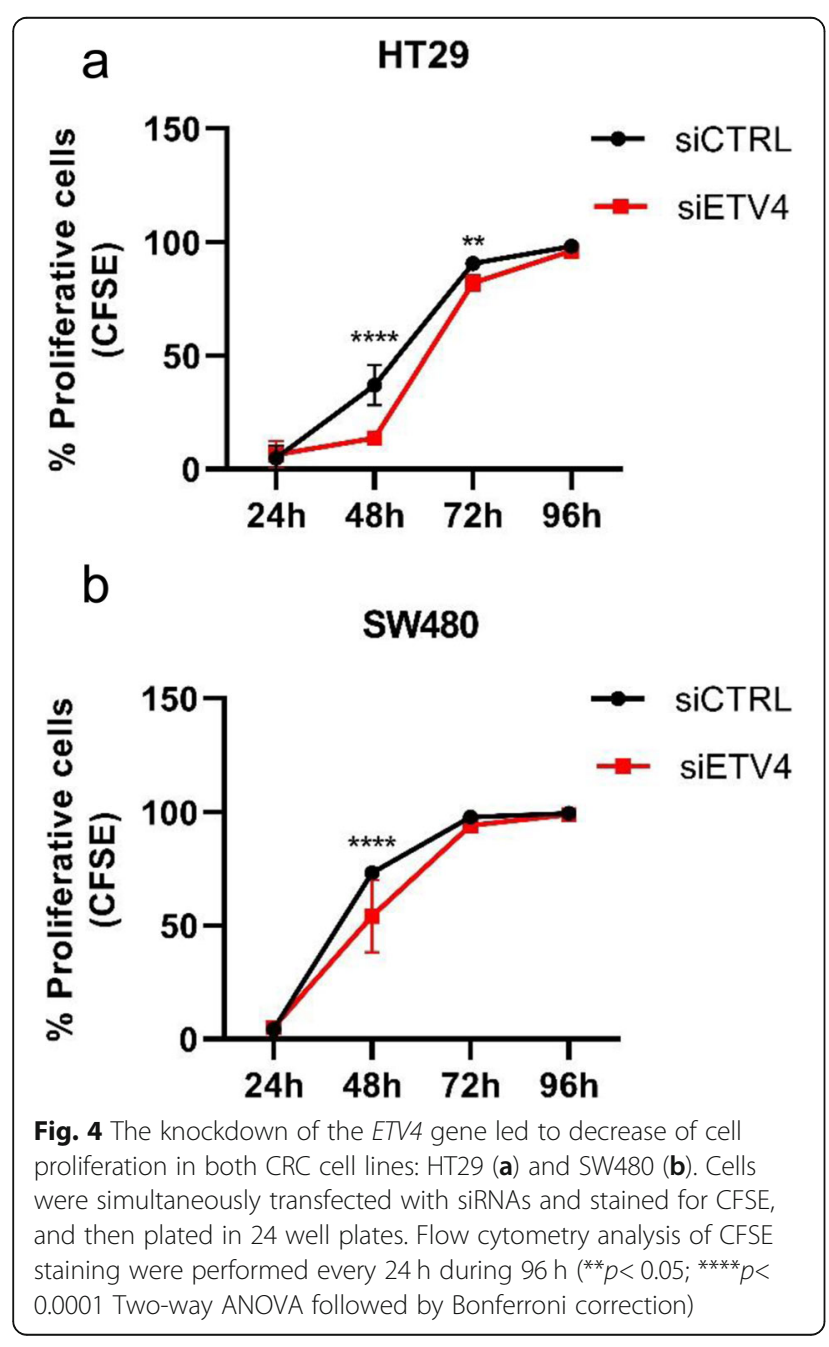

studies have shown the effects of ETV4 silencing in the reduction of cell proliferation, migration and invasion, in both colon and prostate cancer cell lines, but no data on colony formation has been previously associated with ETV4 in CRCs $[49,50]$. Hence, our results suggest that ETV4 is important for the growth of CRC cells.

The reduction in proliferation demonstrated by Hollenhorst et al (2011) [51] in prostate cancer cell lines after ETV4 inhibition was found in combination with a decreased $M Y C$ gene expression, due to the direct regulation of MYC by ETV4. Our findings are in agreement with the reduced proliferation after ETV4 inhibition however, we identified an increase in $M Y C$ gene expression in adenocarcinomas as compared to adenomas.

Previous studies have shown that activation of multiple matrix metalloproteinases plays an important role in tumor invasion by degradation of the extracellular matrix in colorectal cancer [52-55]. MMP1 was identified as a direct or indirect ETV4 target acting on the CRC progression [56]. In a study carried out in nonsmall cell lung cancer [57] the ETV4-MMP1 axis was associated with a poor prognosis. A similar relationship was observed in breast cancer, but for ETV4 and MMP13 [58].

In our samples, only MMP11 (stromelysin-3) was upregulated in adenocarcinoma compared with paired adenoma samples. This metalloproteinase is described in several types of cancer, acting in the proliferation, migration and invasion control [59-61]. In CRC, elevated MMP11 expression was associated with poor prognosis and reduced survival in stage II patients [62]. Serum levels of MMP11 were previously shown to be significantly higher in patients with lymph node metastasis and was also identified as an independent prognostic factor for 5-year mortality in CRC [63]. MMP11 upregulation has also been related to lymph node metastasis in non-small cell lung cancer 


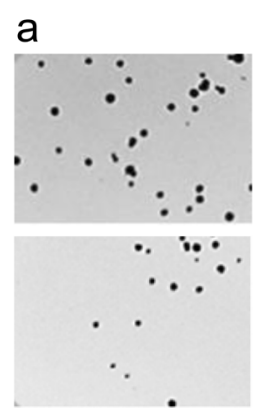

C
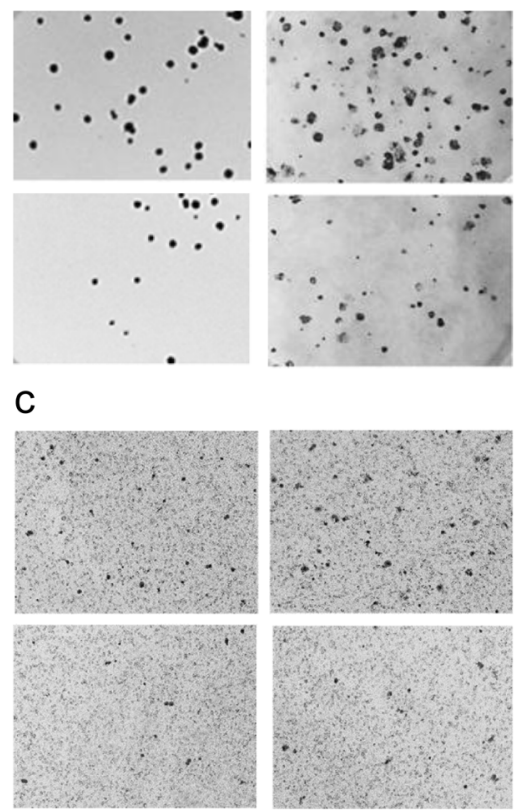

b

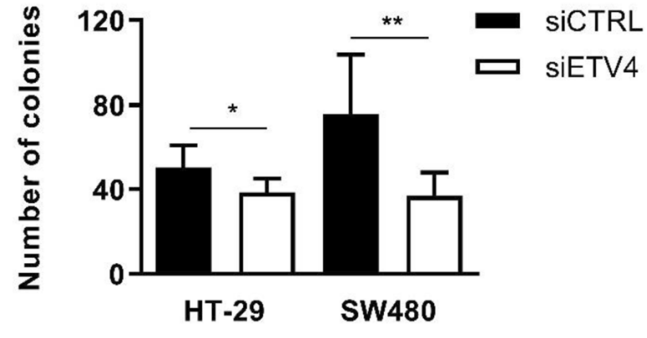

d

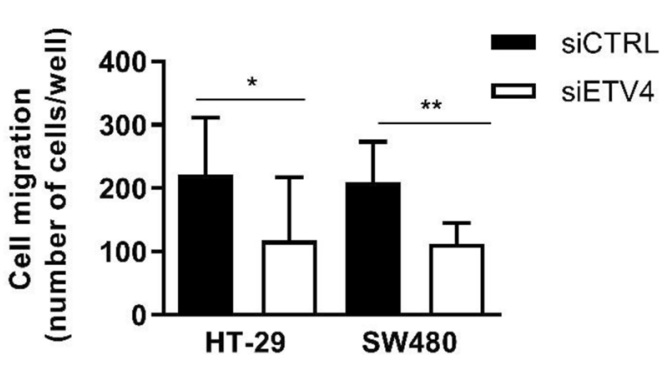

Fig. 5 Knockdown of the ETV4 gene reduced the clonogenic ability and cell migration in the CRC cell lines HT29 and SW480. a Representative images of cell colonies formed after 12 days of culture. $\mathbf{b}$ Bar graph representing the mean of three independent experiments. CRC cells were sparsely plated in 6 well plates (500 cells/well), allowed to grow for 12 days, fixed and stained for manual counting (HT29: $p=0.0402 ;$ SW480: $p=$ 0.0015, Mann-Whitney statistical test). $\mathbf{c}$ Representative images of cell migration. $\mathbf{d}$ Bar graph representing the mean of three independent experiments. Cells were seeded on the top of the insert $\left(1 \times 10^{5}\right)$, fixed $24 \mathrm{~h}$, and stained for manual counting (HT29: $p=0.0231 ;$ SW480: $p=0.0152$, Mann-Whitney statistical test)

and colorectal cancer [64, 65]. Accordingly, MMP11 was upregulated in all our cases that also had compromised lymph nodes. To our knowledge, there is no information available about the relationship between ETV4 and $M M P 11$, so one might speculate that both genes may be involved in lymph node metastasis in CRC. Indeed, ETV4 is related to the embryonic development of different organs, but it is also closely linked to carcinogenesis, especially in metastasis development [66].

Several studies indicate the activation of MMPs by ETV4 [58, 67, 68]. However, it is likely that this activation occurs in dependence of expression and/or functional alterations in other genes involved in the MMP/ ETV4 axis.

\section{Conclusions}

In summary, this study identified a set of differentially expressed genes in CRC, including FcGBP, CLCA1, $A D H 1 C$, COL1A1, ZG16, which could be strong candidates to be used as biomarkers of colorectal adenomaadenocarcinoma progression. Among those genes, ETV4 was further investigated and was shown to act on proliferation and migration of CRC cell lines, indicating that ETV4 could be a robust adenocarcinoma biomarker and a potential target for gene therapy studies in CRC.

\section{Supplementary Information}

The online version contains supplementary material available at https:/doi. org/10.1186/s12885-021-07857-x.

Additional file 1 Table S1. Location and pathological tissue of each patient.

Additional file 2 Table S2. Observed mutations in APC,TP53 and KRAS genes.

Additional file 3 Figure S1. Relative expression of the ETV4 gene after its silencing in HT29 and SW480 CRC cell lines. The silencing was efficient with $p<0,0001$.

Additional file 4 Figure S2. Apoptosis assay. The HT29 and SW480 cell lines did not show any changes in the apoptosis' rates (A) and cell viability (B).

Additional file $\mathbf{5}$ Table S3. Enrichment of signaling pathways analysis.

\section{Abbreviations}

CRC: Colorectal cancer; GALT: Gut-associated lymphoid tissue; HC-FMRP/ USP: Hospital of the Faculty of Medicine of Ribeirão Preto/University of São Paulo; FAP: Familial adenomatous polyposis; HNPCC: Hereditary Non-

Polyposis Syndrome; HRM: High Resolution Melting; PCR: Polymerase Chain Reaction; DEG: Differentially expressed genes; RT-qPCR: Reverse transcription quantitative real time PCR; COAD: Colon adenocarcinoma; READ: Rectal adenocarcinoma; TCGA: The cancer genome atlas; UNESP: University of São Paulo State; RPMI: Roswell Park Memorial Institute; FBS: Fetal bovine serum; siRNA: Small interfering RNA; siCTRL: Small interfering negative control; CFSE: 5(6)-carboxyfluorescein diacetate succinimidyl ester; PBS: Phosphate buffered saline; FDR: False Discovery rate; ECM: Extracellular matrix 


\section{Acknowledgments}

We would like to thank the medical and nursing staff of the department of proctology HC-FMRP-USP for the excellent work in collecting the samples. We wish to thank Amelia Goes Araújo and Adriana Marques Apa technical support in microarray and sequencing respectively. We thank Wagner Nagib de Souza Birbeire for the preparation of the images. We also thank Dr. Luciane R. Cavalli for the comments and final reading of the text.

\section{Authors' contributions}

ASF, CPA, DLZ, DOV, MAZ participated in the study design. MCB, JESS, JRP performed bioinformatics analysis. RAP performed microarray hybridization. ASF, AR, GAM, ARDS, GMA performed the experiments. ASF, AR, LFA, RBLB, analyzed the data. GEBS performed the pathological examination. FMP, OF, JJRR contributed in sample collecting. ASF wrote the paper. GAM, LFA, AR, DLZ helped with manuscript preparation. WASJr supervised the entire project. All authors read and approved the final manuscript.

\section{Authors' information \\ AFFILIATIONS}

Department of Genetics, Ribeirão Preto Medical School, University of São Paulo, USP, Ribeirão Preto, SP, Brazil.

Aline Simoneti Fonseca, Anelisa Ramão, Dalila Lucíola Zanette, Greice Andreotti de Molfetta, Luiza Ferreira de Araújo, Rafaela de Barros e Lima Bueno \& Wilson Araújo Silva Jr.

Center for Cell Based Therapy and National Institute of Science and Technology in Stem Cell and Cell Therapy, Ribeirão Preto, SP, Brazil. Aline Simoneti Fonseca, Anelisa Ramão, Matheus Carvalho Bürger, Jorge Estefano Santana de Souza, Dalila Lucíola Zanette, Greice Andreotti de Molfetta, Luiza Ferreira de Araújo, Rafaela de Barros e Lima Bueno, Graziela Moura Aguiar, Jessica Rodrigues Plaça, Cleidson de Pádua Alves, Anemari Ramos Dinarte dos Santos, Daniel Onofre Vidal, Rodrigo Alexandre Panepucci, Marco Antonio Zago \& Wilson Araújo Silva Jr.

Center for Integrative Systems Biology - CISBi, NAP/USP Ribeirão Preto, SP, Brazil.

Aline Simoneti Fonseca, Dalila Lucíola Zanette, Greice Andreotti de Molfetta, Luiza Ferreira de Araújo \& Wilson Araújo Silva Jr.

Research Institute Pelé Pequeno Príncipe, Curitiba, PR, Brazil.

Aline Simoneti Fonseca.

Departament of Medical Clinic, Medical School of Ribeirão Preto, University of São Paulo, USP, Ribeirão Preto, SP, Brazil. Fernanda Maria Peria.

Laboratory of Immunofluorescence and Electron Microscopy (LIME), Presidente Dutra University Hospital (HUUFMA), São Luís, MA, Brazil. Gyl Eanes Barros Silva.

Departament of Surgery and Anatomy, Medical School of Ribeirão Preto, University of São Paulo, USP Ribeirão Preto, SP, Brazil.

Omar Feres \& José Joaquim Ribeiro da Rocha.

Laboratory of Applied Science and Technology in Health (LASTH), Instituto Carlos Chagas, Fundação Oswaldo Cruz, Curitiba, Brazil. Dalila Luciola Zanette.

\section{CORRESPONDING AUTHORS.}

Correspondence to: Wilson Araújo Silva Jr. and Aline Simoneti Fonseca

\section{Funding}

This work was jointly supported by Coordenação de Aperfeiçoamento de Pessoal de Nível Superior - Brasil (CAPES/PROEX), grant no. 801084; São Paulo Research Foundation (FAPESP), grant no. 2013/08135-2 and by Research Support of the University Sao Paulo, CISBi-NAP/USP, grant no.

12.1.25441.01.2./08135-2.

\section{Availability of data and materials}

The datasets used during this study are available from the corresponding author on reasonable request.

\section{Ethics approval and consent to participate}

The study was approved by the Clinical Hospital of FMRP/USP Research Ethics Committee (No 12636/2010). The consent form was signed by all participants in this study.

\section{Consent for publication}

Not applicable.

\section{Competing interests}

The authors declare that they have no competing interests.

\section{Author details}

'Department of Genetics, Ribeirão Preto Medical School, University of São Paulo, Av Bandeirantes, 3900, CEP: 14049-900, Monte Alegre, Ribeirão Preto, SP, Brazil. ${ }^{2}$ Center for Cell Based Therapy and National Institute of Science and Technology in Stem Cell and Cell Therapy, Ribeirão Preto, SP, Brazil. ${ }^{3}$ Center for Integrative Systems Biology - CISBi, NAP/USP, Ribeirão Preto, SP, Brazil. ${ }^{4}$ Research Institute Pelé Pequeno Príncipe, Av Silva Jardim, 1632, CEP: 80250-060, Água Verde, Curitiba, PR, Brazil. ${ }^{5}$ Laboratory of Applied Science and Technology in Health (LASTH), Instituto Carlos Chagas, Fundação Oswaldo Cruz, Curitiba, PR, Brazil. 'Laboratory of Immunofluorescence and Electron Microscopy (LIME), Presidente Dutra University Hospital (HUUFMA), São Luís, MA, Brazil. 'Departament of Medical Clinic, Medical School of Ribeirão Preto, University of São Paulo, USP, Ribeirão Preto, SP, Brazil. ${ }^{8}$ Department of Surgery and Anatomy, School of Medicine of Ribeirão Preto, University of São Paulo, Sao Paulo, Brazil.

Received: 19 October 2020 Accepted: 31 January 2021

Published online: 01 March 2021

\section{References}

1. World Health Organization. Global Cancer Observatory. International Agency for Research on Cancer (IARC). https://gco.iarc.fr/today/home. Accessed 23 December 2020

2. Hisamuddin IM, Yang WW. Genetics of Colorectal Cancer. MedGenMed. 2004;6(3):13.

3. Muto T, Bussey HJR, Morson BC. The evolution of cancer of the colon and rectum. Cancer. 1975;36:2251-70.

4. Shinya H, Wolff WI. Morphology, Anatomic Distribution and Cancer Potential of Colonic Polyps. Ann Surg. 1979;190(6):679-83.

5. Mäkinen MJ, George SMC, Jernvall P, Mäkelä J, Vihko P, et al. Colorectal carcinoma associated with serrated adenoma - prevalence, histological features, and prognosis. J Pathol. 2001;193(3):286-94.

6. Yamada M, Sekine S, Matsuda T, Yoshida M, Taniguchi H, et al. Dome-type carcinoma of the colon; a rare variant of adenocarcinoma resembling a submucosal tumor: a case report. BMC Gastroenterol. 2012;12:21.

7. Puppa G, Molaro M. Dome-Type: A Distinctive Variant of Colonic Adenocarcinoma. Case Rep Pathol. 2012;2012:284064.

8. Orłowska J. Serrated Polyps of the Colorectum: Histological Classification and Clinical Significance. Pol J Pathol. 2010;1:8-22.

9. Rubio CA, Puppa G, de Petris G, Kis L, Schmidt PT. The third pathway of colorectal carcinogenesis. J Clin Pathol. 2017;0:1-5.

10. Brenner $\mathrm{H}$, Hoffmeister M, Stegmaier $\mathrm{C}$, Brenner G, Altenhofen L, Haug U. Risk of progression of advanced adenomas to colorectal cancer by age and sex: estimates based on 840149 screening colonoscopies. Gut. 2007;56(11): $1585-9$.

11. Miyoshi Y, Ando H, Nagase H, Nishisho I, Horii A. Germ-line mutations of the APC gene in 53 familial adenomatous polyposis patients. Proc Natl Acad Sci. 1992;89:4452-6.

12. Bastien R, Lewis TB, Hawkes JE, Quackenbush JF, Robbins TC, et al. HighThroughput Amplicon Scanning of the TP53 Gene in Breast Cancer Using High-Resolution Fluorescent Melting Curve Analyses and Automatic Mutation Calling. Hum Mutation. 2008;29(5):757-64.

13. Fassina A, Gazziero A, Zardo D, Corradin M, Aldighieri E, Rossi GP. Detection of EGFR and KRAS mutations on transthoracic needle aspiration of lung nodules by high resolution melting analysis. J Clin Pathol. 2009;62:1096-102.

14. Chromas Lite version 2.1 (2012), Technelysium Pty Ltd, South Brisbane, Queensland, Australia.

15. Kumar P, Henikoff $\mathrm{S}, \mathrm{Ng} \mathrm{PC}$. Predicting the effects of coding nonsynonymous variants on protein function using the SIFT algorithm. Nat Protoc. 2009; $4(7): 1073-81$

16. Schwarz JM, Cooper DN, Schuelke M, Seelow D. MutationTaster2: mutation prediction for the deep-sequencing age. Nat Methods. 2014;11(4):361-2.

17. R Core Team. R: A language and environment for statistical computing. Vienna: R Foundation for Statistical Computing; 2018. http://www.R-project.org/

18. Gentleman RC, Carey VJ, Bates DM, Bolstad B, Dettling M, et al. Bioconductor: Open software development for computational biology and bioinformatics. Genome Biol. 2004;5(10):R80. 
19. Kauffmann A, Gentleman R, Huber W. arrayQualityMetrics--a bioconductor package for quality assessment of microarray data. Bioinformatics. 2009; 25(3):415-6.

20. Smyth GK. Limma: linear models for microarray data. In: Gentleman R, Carey V, Dudoit S, Irizarry R, Huber W, editors. Bioinformatics and Computational Biology Solutions using R and Bioconductor. New York: Springer; 2005. p. 397-420.

21. Bolstad BM, Irizarry RA, Astrand M, Speed TP. A comparison of normalization methods for high density oligonucleotide array data based on bias and variance. Bioinformatics. 2003;19:185-93.

22. Benjamini $Y$, Hochberg $Y$. Controlling the false discovery rate: a practical and powerful approach to multiple testing. J R Stat Soc B. 1995;57:289-300.

23. Livak KJ, Schmittgen TD. Analysis of relative gene expression data using real-time quantitative PCR and the 2-DDCT method. Methods. 2001;25: 402-8.

24. Colaprico A, Silva TC, Olsen C, Garofano L, Cava C, Garolini D, Sabedot TS, Malta TM, Pagnotta SM, Castiglioni I, Ceccarelli M, Bontempi G, Noushmehr H. TCGAbiolinks: na R/Bioconductor package for integrative analysis of TCGA data. Nucleic Acids Res. 2016;44(8):e71.

25. Robinson MD, McCarthy DJ, Smyth GK. edgeR: a Bioconductor package for differential expression analysis of digital gene expression data. Bioinformatics. 2010;26(1):139-40.

26. Swift ML. GraphPad prism, data analysis, and scientific graphing. J Chem Inform Comput Sci. 1997;37(2):411-2.

27. Chan SK, Griffith OL, Tai IT, Jones SJM. Meta-analysis of Colorectal Cancer Gene Expression Profiling Studies Identifies Consistently Reported Candidate Biomarkers. Cancer Epidemiol Biomarkers Prev. 2008;17(3):543-52.

28. Jung Y, Lee S, Choi H-S, Kim S-N, Lee E, et al. Clinical Validation of Colorectal Cancer Biomarkers Identified from Bioinformatics Analysis of Public Expression Data. Clin Cancer Res. 2011;17(4):700-9.

29. Chu CM, Yao CT, Chang YT, Chou HL, Chou YC, et al. Gene expression profiling of colorectal tumors and normal mucosa by microarrays metaanalysis using prediction analysis of microarray, artificial neural network, classification, and regression trees. Dis Markers. 2014;(2014):634123.

30. Hauptman N, Boštjančič E, Žlajpah M, Ranković B, Zidar N. Bioinformatics Analysis Reveals Most Prominent Gene Candidates to Distinguish Colorectal Adenoma from Adenocarcinoma. Biomed Res Int. 2018;2018:9416515.

31. Lee S, Bang S, Song K, Lee I. Differential expression in normal-adenomacarcinoma sequence suggests complex molecular carcinogenesis in colon. Oncol Rep. 2006;16(4):747-54

32. Xiong $L$, Wen $Y$, Miao X, Yang Z. NT5E and FcGBP as key regulators of TGF1-induced epithelial-mesenchymal transition (EMT) are associated with tumor progression and survival of patients with gallbladder cancer. Cell Tissue Res. 2014;355:365-74.

33. Yang $B, C a o L$, Liu B, McCaig CD, Pu J. The transition from proliferation to differentiation in colorectal cancer is regulated by the calcium activated chloride channel a1. PLoS ONE. 2013;8(4):e60861.

34. Li X, Hu W, Zhou J, Huang Y, Peng J, et al. CLCA1 suppresses colorectal cancer aggressiveness via inhibition of the Wnt/beta-catenin signaling pathway. Cell Commun Signal. 2017;15(1):38

35. Thiruvengadam SS, O'Malley M, La Guardia L, Lopez R, Wang Z, et al. Gene Expression Changes Accompanying the Duodenal Adenoma-Carcinoma Sequence in Familial Adenomatous Polyposis. Clin Transl Gastroenterol. 2019;10(6):e00053.

36. Parks SK, Pouyssegur J. The $\mathrm{Na}^{+} / \mathrm{HCO}^{-}$Co-transporter SLC4A4 plays a role in growth and migration of colon and breast cancer cells. J Cell Physiol. 2015;230:1954-63.

37. Wu W, Yang Z, Long F, Luo L, Deng Q, et al. COL1A1 and MZB1 as the hub genes influenced the proliferation, invasion, migration and apoptosis of rectum adenocarcinoma cells by weighted correlation network analysis. Bioorg Chem. 2020:95:103457.

38. Chen $X$, Du P, She J, Cao L, Li Y, et al. Loss of ZG16 is regulated by miR$196 a$ and contributes to stemness and progression of colorectal cancer. Oncotarget. 2016;7(52):86695-703.

39. Meng H, Li W, Boardman LA, Wang L. Loss of ZG16 is associated with molecular and clinicopathological phenotypes of colorectal cancer. BMC Cancer. 2018;18(1):433.

40. Eskandari E, Mahjoubi F, Motalebzadeh J. An integrated study on TFs and miRNAs in colorectal cancer metastasis and evaluation of three coregulated candidate genes as prognostic markers. Gene. 2018;679:150-9.
41. Jeong D, Kim H, Kim D, Ban S, Oh S, et al. Defensin alpha 6 (DEFA6) is a prognostic marker in colorectal cancer. Cancer Biomark. 2019;24(4):485-95.

42. Chakroborty D, Emani MR, Klén R, et al. L1TD1 - a prognostic marker for colon cancer. BMC Cancer. 2019;19(1):727.

43. Higashino F, Yoshida K, Fujinaga Y, Kamio K, Fujinaga K. Isolation of a cDNA encoding the adenovirus ElA enhancer binding protein: a new human member of the ets oncogene family. Nucleic Acids Res. 1993;21(3):547-53.

44. Davidson B, Goldberg I, Gotlieb WH, Kopolovic J, Ben-Baruch G, et al. PEA3 Is the Second Ets Family Transcription Factor Involved in Tumor Progression in Ovarian Carcinoma. Clin Cancer Res. 2003;9(4):1412-9.

45. Clementz AG, Rogowski A, Pandya K, Miele L, Osipo C. NOTCH-1 and $\mathrm{NOTCH}-4$ are novel gene targets of PEA3 in breast cancer: novel therapeutic implications. Breast Cancer Res. 2011;13(3):R63.

46. Keld R, Guo B, Downey P, Cummins R, Gulmann C, et al. PEA3/ETV4-related transcription factors coupled with active ERK signalling are associated with poor prognosis in gastric adenocarcinoma. Br J Cancer. 2011;105(1):124-30.

47. Aytes A, Mitrofanova A, Kinkade CW, Lefebvre C, Lei M, et al. ETV4 promotes metastasis in response to activation of PI3-kinase and Ras signaling in a mouse model of advanced prostate cancer. Proc Natl Acad Sci USA. 2013; 110(37):E3506-15.

48. Mesci A, Taeb S, Huang $X$, Jairath $R$, Sivaloganathan D, et al. Pea3 expression promotes the invasive and metastatic potential of colorectal carcinoma. World J Gastroenterol. 2014;20(46):17376-87.

49. Moss AC, Lawlor G, Murray D, Tighe D, Madden SF, et al. ETV4 and Myeov knockdown impairs colon cancer cell line proliferation and invasion. Biochem Biophys Res Commun. 2006;345(1):216-21.

50. Pellecchia A, Pescucci C, De Lorenzo E, Luceri C, Passaro N, et al. Overexpression of ETV4 is oncogenic in prostate cells through promotion of both cell proliferation and epithelial to mesenchymal transition. Oncogenesis. 2012;1:e20.

51. Hollenhorst PC, Ferris MW, Hull MA, Chae H, Kim S, et al. Oncogenic ETS proteins mimic activated RAS/MAPK signaling in prostate cells. Genes Dev. 2011;25(20):2147-57.

52. Deng J, Chen W, Du Y, et al. Synergistic efficacy of Cullin1 and MMP-2 expressions in diagnosis and prognosis of colorectal cancer. Cancer Biomark. 2017;19(1):57-64.

53. Liu H, Zhou B, Wang L, Li Y, Zhou ZG, et al. Association of E1AF mRNA expression with tumor progression and matrilysin in human rectal cancer. Oncology. 2007;73(5-6):384-8.

54. Wang W, Li D, Xiang L, LV M, Tao L, et al. TIMP-2 inhibits metastasis and predicts prognosis of colorectal cancer via regulating MMP-9. Cell Adh Migr. 2019;13(1):273-84

55. Yan Q, Yuan Y, Yankui L, et al. The Expression and Significance of CXCR5 and MMP-13 in Colorectal Cancer. Cell Biochem Biophys. 2015;73(1):253-9.

56. Horiuchi S, Yamamoto H, Min Y, Adachi Y, Itoh F. Association of ets-related transcriptional factor E1AF expression with tumour progression and overexpression of MMP-1 and matrilysin in human colorectal cancer. Pathol. 2003;200(5):568-76.

57. Wang Y, Ding X, Liu B, et al. ETV4 overexpression promotes progression of non-small cell lung cancer by upregulating PXN and MMP1 transcriptionally. Mol Carcinog. 2020;59(1):73-86.

58. Dumortier M, Ladam F, Damour I, et al. ETV4 transcription factor and MMP13 metalloprotease are interplaying actors of breast tumorigenesis. Breast Cancer Res. 2018;20(1):73.

59. Zhang Z, Dong T, Fu Y, et al. MMP-11 promotes papillary thyroid cell proliferation and invasion via the NF-KB pathway [published online ahead of print, 2018 Sep 1]. J Cell Biochem. 2018. https://doi.org/10.1002/jcb.27500.

60. Hsin CH, Chou YE, Yang SF, et al. MMP-11 promoted the oral cancer migration and Fak/Src activation. Oncotarget. 2017;8(20):32783-93.

61. Su C, Wang W, Wang C. IGF-1-induced MMP-11 expression promotes the proliferation and invasion of gastric cancer cells through the JAK1/STAT3 signaling pathway. Oncol Lett. 2018;15(5):7000-6.

62. Eiro N, Carrión JF, Cid S, et al. Toll-Like Receptor 4 and Matrix Metalloproteases 11 and 13 as Predictors of Tumor Recurrence and Survival in Stage II Colorectal Cancer. Pathol Oncol Res. 2019;25(4):1589-97.

63. Pang L, Wang DW, Zhang N, Xu DH, Meng XW. Elevated serum levels of MMP-11 correlate with poor prognosis in colon cancer patients. Cancer Biomark. 2016;16(4):599-607.

64. Delebecq TJ, Porte H, Zerimech F, Copin MC, Gouyer V, et al. Overexpression level of stromelysin 3 is related to the lymph node 
involvement in non-small cell lung cancer. Clin Cancer Res. 2000;6(3): 1086-92.

65. Tian X, Ye C, Yang Y, Guan X, Dong B, et al. Expression of CD147 and matrix metalloproteinase-11 in colorectal cancer and their relationship to clinicopathological features. J Transl Med. 2015;27(13):337.

66. de Launoit Y, Chotteau-Lelievre A, Beaudoin C, Coutte L, Netzer S, et al. The PEA3 group of ETS-related transcription factors. Role in breast cancer metastasis. Adv Exp Med Biol. 2000;480:107-16.

67. Qi M, Liu Z, Shen C, Wang L, Zeng J, et al. Overexpression of ETV4 is associated with poor prognosis in prostate cancer: involvement of UPA UPAR and MMPs. Tumour Biol. 2015;36(5):3565-72.

68. Yamamoto H, Horiuchi S, Adachi Y, Taniguchi H, Nosho K, et al. Expression of ets-related transcriptional factor E1AF is associated with tumor progression and over-expression of matrilysin in human gastric cancer. Carcinogenesis. 2004;25(3):325-32.

\section{Publisher's Note}

Springer Nature remains neutral with regard to jurisdictional claims in published maps and institutional affiliations.

Ready to submit your research? Choose BMC and benefit from:

- fast, convenient online submission

- thorough peer review by experienced researchers in your field

- rapid publication on acceptance

- support for research data, including large and complex data types

- gold Open Access which fosters wider collaboration and increased citations

- maximum visibility for your research: over $100 \mathrm{M}$ website views per year

At BMC, research is always in progress.

Learn more biomedcentral.com/submissions 